Running head: LEXICAL STRESS CUES IN LEXICAL-SEMANTIC

ACTIVATION

Perception of Lexical Stress by Brain-damaged Individuals: Effects on Lexical-Semantic Activation

Auxiliary short title: Perception of Lexical Stress by Brain-damaged Individuals

Amee P. Shah and Shari R. Baum

School of Communication Sciences and Disorders, McGill University, Montreal, Quebec, Canada

Author to whom correspondence should be addressed:

Amee P. Shah

Department of Speech and Hearing

Cleveland State University

2121 Euclid Avenue, MC 430

Cleveland, OH 44115-2214

Email: a.shah101@csuohio.edu

Tel: 216-687-6988

Fax: 216-687-6993 


\begin{abstract}
A semantic priming, lexical-decision study was conducted to examine the ability of leftand right-brain damaged individuals to perceive lexical-stress cues and map them onto lexical-semantic representations. Correctly- and incorrectly-stressed primes were paired with related and unrelated target words to tap implicit processing of lexical prosody. Results conformed with previous studies involving implicit perception of lexical stress, in that the left-hemisphere damaged individuals showed preserved sensitivity to lexical stress patterns as indicated by priming patterns mirroring those of the normal controls. An increased sensitivity to the varying stress patterns of the primes was demonstrated by the right-hemisphere-damaged patient group, however. Results are discussed in relation to current theories of prosodic lateralization, with a particular focus on the nature of task demands in lexical stress perception studies.
\end{abstract}

Keywords: lexical stress, speech perception, prosody, lexical activation, semantic activation, brain-damaged, hemispheric specialization, prosodic lateralization. 


\section{PERCEPTION OF LEXICAL STRESS BY BRAIN-DAMAGED INDIVIDUALS: EFFECTS ON LEXICAL-SEMANTIC ACTIVATION}

\section{Introduction}

Converging evidence from psycholinguistic research has unequivocally established the importance of lexical prosody in metrical segmentation and word recognition in healthy adult listeners (Connine et al., 1987; Cutler \& Norris, 1988; Taft, 1984; Heuven, 1985; Slowiaczek, 1990). Studies have shown that, in English, lexical stress cues listeners to identify word-onsets from a continuous stream of speech ("metrical segmentation strategy”, e.g., Cutler \& Norris, 1988; Mattys \& Samuel, 1997; McQueen, Norris \& Cutler, 1994; Norris, McQueen \& Cutler, 1995; Grosjean \& Gee, 1987; Taft, 1984). Strong or stressed syllables have been found to be reliable cues not only in identifying actual word-onsets in word-initial position, but they also serve to trigger lexical access in other positions in a word (Mattys \& Samuel, 1997). Further, errors of lexical stress or impaired processing of lexical stress result in impaired word identification (Mattys \& Samuel, 1997). For example, Connine et al. (1987) presented listeners with stimuli from synthetic VOT continua in which the initial stop consonant varied from $/ \mathrm{d} / \mathrm{to} / \mathrm{t} /$; the endpoint stimuli also varied in canonical stress pattern (e.g. diGRESS-tiGRESS/ DIgressTIgress). Listeners were required to categorize the ambiguous initial segments.

Responses revealed an influence of lexical stress information on identification of ambiguous segments as evidenced by the fact that listeners were more likely to report a segment that was consistent with a real word's stress pattern (e.g. diGRESS or TIgress) than one that resulted in what might be considered a nonword (e.g. DIgress or tiGRESS). 
These results point to an effect of lexical stress in identifying phonetically ambiguous words.

Gating experiments have shown that the availability of prosodic information enhances word recognition relative to conditions in which only word-onset and/or wordlength information is available to listeners; this prosodic advantage holds up even at gates as short as $50 \mathrm{~ms}$ (Lindfield, Wingfield \& Goodglass, 1999; Wayland, Wingfield \& Goodglass, 1989; Wingfield, Goodglass \& Lindfield, 1997). Further, Slowiaczek (1990) found that both shadowing and lexical decisions to auditorily-presented words were facilitated in young, neurologically-intact adults when the stimuli were produced with correct rather than incorrect lexical stress, e.g., ANgry versus anGRY. In contrast, in tests of word recognition in noise, the advantage provided by accurate prosodic information is reduced, presumably due to the increased redundancy available in such an off-line task (Slowiaczek, 1990).

Despite increased evidence from both neuroimaging and electrophysiological data from neurologically-intact adults, as well as behavioral data from brain-damaged patients concerning the neural representation of prosodic processing (see Baum \& Pell, 1999, for a review; Poeppel, 2001; Gandour et al. 2003), it is not yet clear what brain regions are implicated in the perception of lexical stress. Studies of neurologically-impaired populations addressing the perception of lexical stress have mainly shown impairments in individuals who have suffered left-hemisphere damage (LHD) relative to those who have suffered right-hemisphere damage (RHD) (e.g. Baum, 1998; Baum, Kelsch, Daniloff, Daniloff \& Lewis, 1982; Emmorey 1987, but c.f. Bradvik, Dravins, Holtas, Rosen, Ryding \& Ingvar, 1991; Weintraub, Mesulam \& Kramer, 1981). For example, using a 
picture-identification task, Baum et al. (1982) compared LHD and normal individuals on their ability to identify compound noun/noun phrase contrasts cued mainly by stress differences (e.g. greenhouse versus green house). Results showed that the LHD patients were impaired in their ability to correctly identify the intended meanings. Similarly, Emmorey (1987) found a significant impairment in LHD patients' ability to comprehend phonemic stress relative to RHD and normal control subjects using similar stimuli. In an attempt to determine whether LHD and RHD patients were differentially impaired in the perception of particular acoustic cues to stress (e.g. Van Lancker and Sidtis, 1992), Baum (1998) compared LHD and RHD patients on their ability to perceive lexical or phonemic as well as emphatic stress contrasts in two acoustically-edited stimulus-types, an F0neutralized and a duration-neutralized set. Responses were tested in contexts of pictureidentification (to test phonemic stress contrasts) and highlighted (i.e., bold print) nounidentification in written stimuli (to test emphatic stress contrasts). Results showed identification of phonemic stress contrasts was at chance level for the LHD individuals in all conditions; identification of emphatic stress contrasts was also at chance in the F0neutralized condition. Unlike the LHD individuals, the RHD individuals appeared to benefit from the availability of the full range of acoustic cues in the full-cue condition, as indicated by their better than chance performance in only the full-cue condition of the phonemic stress subtest. In the emphatic stress subtest, the RHD patients showed better than chance identification in all conditions, unlike the difficulties exhibited by LHD patients with F0-neutralized stimuli. Thus, consistent with previous studies (Baum et al., 1982, Emmorey, 1987), although the RHD were not completely normal in the perception of lexical stress, their impairments, however, appear to be not as marked as those of the 
LHD patients; thus, taken together, these studies support a LH dominance in the perception of lexical stress.

Of note, as is typical of most investigations of receptive prosodic abilities in brain-damaged individuals (Lehtihalmes \& Latvala, 1993; Geigenberger \& Ziegler, 2001; Pell, 1998), the studies described above made use of explicit off-line experimental tasks, i.e., tasks wherein the instructions overtly direct subjects' attention to, and involve their participation in, the process to be examined. Such tasks are likely to involve processes different from those required during normal language comprehension (Tyler, Cobb, \& Graham, 1992). Implicit tasks, on the other hand, provide instructions that engage subjects in a distractor task that is only indirectly reflective of the process to be examined. For example, Baum (2002) tested brain-damaged patients' sensitivity to lexical stress patterns, as reflected in lexical decision latencies and accuracy. Results indicated preserved sensitivity to stress patterns in LHD patients, as evidenced by increased response latencies and errors on incorrectly stressed words. Not surprisingly, 8 of 10 RHD patients also showed a similar pattern of preserved sensitivity to stress patterns. Thus, it appears that the implicit processing of lexical stress cues may be preserved in LHD patients, despite difficulties reported for explicit tasks (Baum, 1998; Baum et al., 1982; Emmorey, 1987). Indeed, other studies have shown that LHD patients show preserved implicit processing of lexical stress, prosodic focus, and phrase boundary marking (Kimelman, 1999; Kimelman \& McNeil, 1987, Swinney, Zurif, \& Cutler, 1980; Walker, Fongemie, \& Daigle, 2001).

Wunderlich, Ziegler, \& Geigenberger (2003) attempted to address the somewhat disparate findings by directly comparing sensitivity to prosodic cues in implicit and 
explicit tasks in brain-damaged patients. Comprehension of sentence-level focus was examined using a phoneme-monitoring paradigm (the implicit task) and a focusidentification task (the explicit task). In the phoneme-monitoring task, unrelated sentence pairs, whose structure allowed for two different prosodic focus markings on target content words, formed the stimuli. In each sentence, a word was selected such that it began with one of 10 target consonants for which listeners were required to monitor. In one of the two sentences of each pair, the word beginning with the target consonant carried stress, and in the other sentence, the stress was shifted to a word other than the target-bearing word. The expectation was that monitoring latencies would be faster in cases where the target phoneme occurred in a stressed word as opposed to in an unstressed one. Results showed that LHD participants produced higher phonemedetection error rates and longer response times relative to both normal controls and RHD patients, as might be expected from deficits in phonological processing typical of LHD aphasic patients. Somewhat surprisingly, and counter to the functional lateralization hypothesis of prosodic processing (Van Lancker, 1980), the LHD patients, like the other groups, showed longer latencies in the unaccented condition than the accented one, suggesting their responses were influenced by stress patterns, implying preserved perception of the acoustic cues to lexical stress information in this implicit task. For the explicit focus identification task, subjects listened to sentences with prosodic focus marked on one of four elements — actor, place, time and action — and were required to decide which of the four categories bore the focus. The findings demonstrated a large number of focus identification errors in the LHD patients relative to both RHD patients and normal controls, supporting the notion that the impairment in the LHD patients was 
due to the metalinguistic nature of the task rather than a deficit in prosodic processing per se.

While the above experiments make a sound case for considering the explicit versus implicit nature of the tasks in resolving discrepant findings across studies, it remains unclear whether the deficits exhibited by LHD patients in tasks tapping the processing of lexical stress emerge only when tasks require explicit metalinguistic judgments of prosody or rather when the tasks require further linguistic processing of any kind (e.g., activation of word meaning). In an effort to address this question, the present investigation explored brain-damaged patients' sensitivity to lexical stress manipulations in an associative priming task that requires both extraction of the prosodic information and the activation of word meaning. Results should address whether LHD participants (previously shown to exhibit sensitivity to stress cues per se (Baum, 2002; Wunderlich et al., 2003)) are able to use lexical stress cues to activate lexical-semantic representations in a manner comparable to normal subjects.

\section{METHOD}

\section{Subjects}

Thirty-three subjects participated in the study: 10 left-hemisphere damaged (LHD) nonfluent aphasic patients, nine right-hemisphere damaged (RHD) patients, and 14 age-matched non-brain-damaged control (NC) subjects. All were native English speakers with hearing within normal limits (PTA bilaterally $<30 \mathrm{~dB}$ at frequencies of $0.5,1$, and $2 \mathrm{kHz}$ ). As indicated from their medical records, the brain-damaged patients had all suffered a single, unilateral CVA, and at the time of participation in this study, 
they were all at least 20 months post onset of the CVA (range=22-157 months).

Additional details regarding the background information of the three subject groups are provided in Table 1.

All brain-damaged subjects underwent a battery of screening tests including sections of the Psycholinguistic Assessment of Language (Caplan, 1992), Mini Mental State Examination (Folstein et al., 1975), the Behavioural Inattention Test (Wilson et al., 1987), and the Discourse Comprehension Test (Brookshire \& Nicholas 1993) to ensure adequate reading skills, auditory comprehension, auditory memory, discourse comprehension, and to rule out visual neglect. In addition, the LHD patients were administered sections from the Boston Diagnostic Aphasia Examination (Goodglass \& Kaplan 1983) and the Boston Naming Test (Kaplan et al., 1983) to characterize their difficulties with verbal expression, as only nonfluent aphasic patients were included in the group. Correspondingly, the RHD patients were administered additional screening tests to tap problems typically associated with right hemisphere brain damage, including difficulties with drawing inferences and interpreting figurative language, as well as difficulties with perception of emotional prosody (sections derived from the Test of Language Competence-Expanded Edition, Wiig \& Secord, 1989). Only those individuals with impairments on at least one of these tests were included as participants.

\section{Stimuli}

Twenty words, selected as primes, were produced in two versions - correctly stressed (CS) or incorrectly stressed (IS) - to appear with semantically-related (R) or unrelated (UR) target words. The primes were selected to be common nouns, two 
syllables in length, and matched for frequency of occurrence (Mean=91, SD=107; Francis and Kucera, 1982). Related target words, to be paired with these primes, were selected from a word-association data-base (Nelson, McEvoy \& Schreiber, 1998) such that they were matched for associative strength across the prime-target pairs. Additionally, the related targets were matched for length and frequency of occurrence (Mean=219, $\mathrm{SD}=125)$ with the corresponding unrelated targets (Mean=193, $\mathrm{SD}=106)$ for each primetarget pair.

Equal numbers of nonword targets $(\mathrm{n}=20$ each) were paired with parallel sets of CS ( $n=20)$ and IS $(n=20)$ Filler prime words. The nonword targets, like the real word targets, were all two syllables in length. Table 2 provides examples of primes and targets in each of the trial types. Note that the location of lexical stress is indicated by capitalized text. Appendix 1 provides a complete list of stimuli.

The stimuli —a total of 20 CS-R, 20 CS-UR, 20 IS-R, 20 IS-UR, and 40 fillerNW pairs (listed in Appendix 1) — were recorded by an adult female native speaker of English using Sony TCD-D100 DAT recorder and a head-mounted directional microphone (AKG Acoustics C420) set at a fixed mic-to-mouth distance throughout the recording session. Since the majority of primes were stressed on the first syllable in the CS condition, the speaker recorded the associated IS words by shifting the stress to the second syllable; (for the remaining 7 of 40 primes, the IS word was produced by shifting the stress from the original second syllable stress to the first syllable). The associated correctly- and incorrectly-stressed words were recorded sequentially in an effort to preserve the allophonic variation patterns. The speaker was given sufficient time before recording to become familiar with the stimuli and a research assistant monitored 
productions to ensure that appropriate stress and allophonic patterns were produced and that recording levels remained consistent throughout the session. The recorded stimuli were digitized at a sampling rate of $20 \mathrm{kHz}$ with a $9 \mathrm{kHz}$ low-pass filter and 12-bit quantization using the Brown Lab Interactive Speech System (BLISS) software (Mertus, 1989).

The stimuli pairs were divided into two lists (one list per session) to avoid target repetition within a list. In a given list, for any given stimulus, if the prime-target combination CS-R appeared, then the associated IS-UR pair appeared; if a specific IS-R pair appeared, then the corresponding CS-UR pair appeared. In both lists, Filler prime words $(n=40)$ were paired with NW targets $(n=40)$ such that the CS and IS versions of the Filler primes were similarly split across the two lists. Thus, each list consisted of forty critical prime-target pairs and forty Filler prime-NW target pairs, yielding 80 trials in each list.

\section{Procedure}

The subjects were tested in two individual sessions (one per list) of approximately 40 minutes each, separated by at least one week. In each session, one of the two lists of stimuli was presented to subjects in random order over closed headphones with a $250 \mathrm{~ms}$ interstimulus interval (ISI) ${ }^{1}$ and a $5 \mathrm{~s}$ intertrial interval (ITI). The order of lists was counterbalanced across subjects in each group. Subjects indicated their lexical decision response by pressing a "yes" or "no" button on a response box in front of them. Subjects were instructed to listen to the word pairs and make word/non-word decisions about the

\footnotetext{
${ }^{1}$ The ISI was chosen to be relatively brief, but to ensure a perceptible pause between stimuli so that braindamaged participants would be able to easily identify the target word for lexical decision.
} 
second word in each pair. They were asked to respond as quickly and accurately as possible, using their currently dominant hand. The computer recorded response accuracy as well as reaction times (in ms) from the onset of the targets. A short practice session of six additional trials, comprised of one example of each stimulus type preceded the presentation of the test stimuli in each of the two individual sessions.

\section{RESULTS}

Errors in lexical decision responses for each subject were examined separately for each list; because no marked discrepancy in error rate was noted across the two lists, all further analyses were performed on the collapsed lists. Collapsing across the four real word conditions, the NC group made a total of $1.25 \%$ errors; the LHD group made $4 \%$ and the RHD group made $3.89 \%$ errors $^{2} .$. As illustrated in Figure 1, there were slightly more errors for the unrelated target conditions for all groups, but most notably for both brain-damaged patient groups. Because error rates were low, no statistical analyses were conducted on the error data.

Outliers, defined as trials with RTs greater or less than 2 standard deviations from the mean for that condition for each participant, were identified and eliminated from each of the four real word conditions. The total percentages of data eliminated within each group (including both errors and outliers) were $5.18 \%$ in the NC group, $9.5 \%$ in the LHD group and $8.33 \%$ in the RHD group.

Figure 2 illustrates the mean RTs (for correct responses only) for each group in each condition. The results suggest a largely similar pattern across the groups, with faster RTs to related targets relative to unrelated targets in both CS and IS

\footnotetext{
2 These percentages reflect total numbers of errors, not mean numbers of errors.
} 
conditions. Individual RT data are provided in Table 3 and will be discussed below. A three-way Group (NC, LHD, RHD) x Stress condition (CS, IS) x Semantic relatedness (R, UR) analysis of variance (ANOVA) on RTs for correct responses to real word targets yielded main effects of Group $[\mathrm{F}(2,30)=3.745, \mathrm{p}<0.05]$ and Semantic relatedness $[\mathrm{F}(1$, $30)=111.560, \mathrm{p}<0.001]$, and a three-way interaction among Group, Stress condition and Semantic relatedness $[\mathrm{F}(2,30)=3.711, \mathrm{p}<0.05]$. Post-hoc analysis of the interaction using the Newman-Keuls procedure $(\mathrm{p}<.05)$ revealed significantly faster RTs to related targets in both stress conditions in all groups. In addition, for the LHD patients, RTs to unrelated targets were significantly slower in the IS compared to the CS condition; for the RHD patients, this pattern was reversed, with RTs to unrelated targets in the CS condition slower than in the IS condition. For the NC participants, RTs to unrelated targets did not differ as a function of stress condition.

In examining the individual data provided in Table 3, it is first quite apparent that there is a good deal of individual variability within each group. Nonetheless, the vast majority of subjects in each group display semantic facilitation in both stress conditions. What is less consistent is the effect of stress. That is, whereas the post hoc analyses revealed significantly slower RTs in the IS-UR condition compared to the CS-UR condition for the LHD patients, only 4 of the 10 participants actually exhibited such a difference (LHD5, 6, 8, 9, with LHD6 perhaps accounting for the majority of the effect). Within the RHD group, patterns were more consistent, with 7 of the 9 participants conforming to the group pattern. There were no obvious characteristics differentiating those individuals whose performance diverged from those of the rest of the group. 


\section{DISCUSSION}

The goal of the present investigation was to determine whether impairments in lexical stress processing in LHD aphasic patients emerge in a task that requires (implicit) activation of word meaning but does not require metalinguistic judgments concerning prosody or explicit access to lexical semantics. To this end, a primed lexical decision task was administered to groups of LHD and RHD patients and a group of non-brain-damaged participants. In keeping with previous investigations that have examined implicit prosodic processing at the lexical level (e.g., Baum, 2002; Wunderlich et al., 2003), the findings are consistent with preserved sensitivity to lexical stress patterns in the LHD aphasic patients, whose priming patterns, as reflected in lexical decision latencies, largely mirrored those of the NC participants.

Interestingly, although the statistical analyses would suggest that the LHD aphasic patients seemed to be somewhat more influenced by the anomalous stress patterns in the primes than were the normal controls (in that their RTs in the incorrectly-stressed, unrelated target condition (IS-UR) were significantly longer than in the correctlystressed, unrelated condition (CS-UR)), examination of the individual data suggest that the group pattern may not accurately reflect the performance of the majority of participants. In fact, it seems that the data for most of the LHD aphasic patients were consistent with those of the NC subjects, whose latencies to the unrelated targets (and the related targets - see below) were not significantly influenced by the stress patterns of the primes. Of interest in this regard, however, were the results for the RHD patients, who displayed significantly different RTs to unrelated targets preceded by correctly- and 
incorrectly-stressed primes; however, in contrast to the pattern for the LHD aphasic patients as a group, the RHD participants' latencies (as a group and for the majority of individuals) were slower in the CS-UR condition relative to the IS-UR condition. This result is particularly surprising, and suggests that while the RHD patients were sensitive to the prosodic differences in the primes, they were perhaps more influenced by what might be considered "conflicting" information in the prime-target pair — that is, correct stress in the prime but an unrelated target (in contrast to the IS-UR condition in which the incorrect stress can be said to be in accord with, or match, the unrelated target). One might hypothesize that a parallel difference did not emerge in the related target conditions due to the semantic facilitation effect overriding any potential influence of the so-called "conflicting" information.

The fact that the anomalous stress patterns of the primes in the IS conditions did not influence response latencies for the NC participants may at first appear somewhat surprising. That is, previous investigations have demonstrated that lexical stress has an important influence on word recognition (e.g., Baum, 2002; Slowiaczek, 1990). Those investigations examined access to the correctly- (CS) or incorrectly-stressed (IS) word itself. In contrast, in the present investigation, RTs were gathered on responses to appropriately-stressed target words that were preceded by CS or IS primes. Even if recognition of the IS primes were slowed compared to the CS primes, the $250 \mathrm{~ms}$ ISI, coupled with the relatively long RTs of the older normal participants (averaging over $1000 \mathrm{~ms}$ ) may have provided sufficient time to 'recover' from any delay in activation induced by the IS primes. A similar hypothesis might be posited for the majority of LHD aphasic patients. Whereas one might argue that the failure to find an effect of anomalous 
stress patterns on the RTs of the NC participants undermines, to some extent, any claims concerning sensitivity to stress on the part of the brain-damaged individuals, we believe that the stress-related differences that were found for the RHD patients in the unrelated conditions indeed support their sensitivity to lexical stress patterns and the influence of stress on word recognition in general. Coupled with data from previous investigations (e.g., Wunderlich et al., 2003; Baum 2002; Kimelman, 1999; Kimelman and McNeil, 1987; Swinney, Zurif and Cutler, 1980; Walker et al, 2001), the findings may be interpreted as suggestive of intact implicit processing of lexical-level prosody in the brain-damaged patients tested.

Taken together, the present findings suggest that individuals with LHD, as well as those with RHD, retain sensitivity to lexical prosody in English (see also Baum, 2002; Wunderlich et al., 2003). Impairments on the part of LHD aphasic patients in lexical prosodic perception in previous studies may, thus, not reflect deficits in the perception of prosodic cues per se, but rather in the interpretation of those cues in a linguisticallysignificant way (as reflected in metalinguistic judgments of prosody or in interpretation of prosodic parameters that signal meaning differences among words).

From a different perspective, it is perhaps not surprising that the LHD participants were able to access the incorrectly-stressed words and thereby activate semantic associates in a relatively normal manner. Numerous studies have shown a greater-thannormal reliance on the part of certain LHD aphasic patients on top-down or contextual information in language processing (e.g., Caplan \& Aydelott-Utman, 1994; Blumstein et al., 1994; but cf. Boyczuk \& Baum, 1999). Under this view, in the present experiment, despite incorrect stress information in the IS primes, the remaining phonological form 
information and thus the lexical information were compatible with only a single lexical candidate. Given the lexical activation based on the phonology, the lower-level prosodic (mis)information may have been overridden by the lexical-level activation patterns, assuming such LHD patients rely more heavily on top-down biases. On the other hand, some studies have suggested that LHD nonfluent aphasic patients require a practically 'perfect match' to activate a lexical candidate, failing to display priming in (phonologically) mediated priming tasks (e.g., Milberg et al., 1988; but cf. Baum, 1997). However, these tasks reflect a more significant mismatch than the stress mismatch utilized in the present investigation, in that word onset phonology is misleading to the listener in such mediated priming tasks.

In sum, whereas the present findings are not entirely compatible with any current theory of the neural bases of prosody, nor do they directly refute any of the current theories. The results may be interpreted as consistent with a number of recent investigations that have reported intact prosodic processing at the lexical level in implicit tasks (e.g., Wunderlich et al., 2003; Baum 2002; Kimelman, 1999; Kimelman and McNeil, 1987; Swinney, Zurif and Cutler, 1980; Walker et al, 2001), highlighting the importance of a consideration of task demands in interpreting results of prosodic processing investigations. Future investigations that systematically manipulate task demands using comparable stimuli should help to resolve this issue. For example, one might utilize stimuli similar to those in the present investigation, but require semantic relatedness judgments rather than lexical decisions to tap more explicit processing. Similarly, one might employ a single word lexical decision task, presenting related and unrelated pairs in sequence, but not drawing attention to the paired nature of the stimuli, 
and requiring decisions on each stimulus presented. This would permit, within the same experiment, an analysis of sensitivity to the stress patterns as reflected in RTs to both the mis-stressed word itself and to effects on possible associative priming. There are, of course, numerous possible future directions; the critical point is that the potential role of task demands cannot be overlooked. 


\section{Acknowledgments}

This research was supported by a grant from the Canadian Institutes of Health Research (MOP-11290) to Shari Baum. The assistance of Pablo Ruiz and Lisa Trayhern with data collection is greatly appreciated. 


\section{References}

Baum, S. (1997). "Phonological, semantic, and mediated priming in aphasia." Brain and Language, 60, 347-359.

Baum, S. (1998). The role of fundamental frequency and duration in the perception of linguistic stress by individuals with brain damage. Journal of Speech, Language \& Hearing Research, 41, 31-40.

Baum, S. (2002). Word recognition in individuals with left and right hemisphere damage: The role of lexical stress. Applied Psycholinguistics, 23, 233-246.

Baum, S., Kelch Daniloff, J., Daniloff, R., \& Lewis, J. (1982). Sentence comprehension by Broca's aphasics: Effects of some suprasegmental variables. Brain and Language, 17, 261-271.

Baum, S., \& Pell, M. (1999). The neural bases of prosody: Insights from lesion studies and neuroimaging. Aphasiology, 13, 581-608.

Blumstein, S., Burton, M., Baum, S., Waldstein, R., \& Katz, D. (1994). The role of lexical status on the phonetic categorization of speech in aphasia. Brain and Language, 46, 181-197.

Boyczuk, J., \& Baum, S. (1999). The influence of neighborhood density on phonetic categorization in aphasia. Brain and Language, 67, 46-70.

Brådvik, B., Dravins, C., Holtås, S., Rosen, I., Ryding, E., \& Ingvar, D. (1991). Disturbances of speech prosody following right hemisphere infarcts. Acta Neurologica Scandinavica, 84 (2), 114-126.

Brookshire, R.H., \& Nicholas, L.E. (1993). Discourse Comprehension Test. Minneapolis, Minnesota: BRK Publishers. 
Caplan, D. (1992). Language: Structure, process, and disorders. Cambridge, MA: MIT Press.

Caplan, D., \& Aydelott-Utman, J. (1994). Selective acoustic-phonetic impairment and lexical access in an aphasic patient. Journal of the Acoustical Society of America, $95,512-517$.

Connine, C. M., Clifton, C. Jr., \& Cutler, A. (1987). Effects of lexical stress on phonetic categorization. Phonetica, 44, 133-146.

Cutler, A., \& Norris, D. (1988). The role of strong syllables in segmentation for lexical access. Journal of Experimental Psychology: Human Perception and Performance, 14 (1), 113-121.

Emmorey, K. (1987). The neurological substrates for prosodic aspects of speech. Brain and Language, 30, 305-320.

Folstein, M. F., Folstein, S. E., \& McHugh, P. R. (1975). "Mini-mental state": A Practical method for grading cognitive state of patients for the clinician. Journal of Psychiatric Research, 12, 189-198.

Francis, W. N., \& Kucera, H. (1982). Frequency analysis of English usage. Boston: Houghton Mifflin.

Gandour, J., Dzemidzic, M., Wong, D., Lowe, M., Tong, Y., Hsieh, L., Satthamnuwong, N., \& Lurito, J. (2003). Temporal integration of speech prosody is shaped by language experience: An fMRI study. Brain and Language, 84, 318-336.

Geigenberger, A., \& Zeigler, W. (2001). Receptive prosodic processing in aphasia. Aphasiology, 15, 1169-1188.

Goodglass, H., \& Kaplan, E. (1983). The assessment of aphasia and related disorders. 
Philadelphia, PA: Lea and Febiger.

Grosjean,F., \& Gee, J. P. (1987). Prosodic structure and spoken word recognition. Cognition, 25, 135-155.

Heuven, V. J. van (1985). Perception of stress pattern and recognition: Recognition of Dutch words with incorrect stress position. Journal of the Acoustical Society of America, 78, S21.

Kaplan, E., Goodglass, H., \&. Weintraub, S. (1983). Boston Naming Test. Philadelphia, PA: Lea and Febiger.

Kimelman, M. D. Z. (1999). Prosody, linguistic demands and auditory comprehension in aphasia. Brain and Language, 69, 212-221.

Kimelman, M. D. Z., \& McNeil, M. (1987). An investigation of emphatic stress comprehension in adult aphasia: A replication. Journal of Speech and Hearing Research, 30, 295-300.

Lehtihalmes, M. \& Latvala, K. (1993). Comprehension of prosody after brain infarction. Poster auf der 3. Tagung der International Clinical Linguistics and Phonetics Association, Helsinki.

Lindfield, K. C., Wingfield, A., \& Goodglass, H. (1999). The contribution of prosody to spoken word recognition. Applied Psycholinguistics, 395-405.

Mattys, S. L. \& Samuel, A. G. (1997). How lexical stress affects speech segmentation and interactivity: Evidence from the migration paradigm. Journal of Memory and Language, 36 (1), 87-116.

McQueen, J. M., Norris, D., \& Cutler, A. (1994). Competition in spoken word recognition: Spotting words in other words. Journal of Experimental Psychology: 
Learning, Memory and Cognition, 20, 621-638.

Mertus, J. (1989). BLISS user's manual. Providence, RI: Brown University.

Milberg W., Blumstein, S. \& Dworetzy, B. (1988). Phonological factors in lexical access:

evidence from an auditory lexical decision task. Bulletin of the Psychonomic Society, 26, 305-308.

Nelson, D. L., McEvoy, C. L., \& Schreiber, T. A. (1998). The University of South Florida word association, rhyme, and word fragment norms. http://www.usf.edu/FreeAssociation/.

Norris, D., McQueen, J. \& Cutler, A. (1995). Competition and segmentation in spoken word recognition. Journal of Experimental Psychology: Learning, Memory, and Cognition, 21, 1209-1228.

Pell, M. D. (1998). Recognition of prosody following unilateral brain lesion: influence of functional and structural attributes of prosodic contours. Neuropsychologia, 36, 701-715.

Poeppel, D. (2001). Pure word deafness and the bilateral processing of the speech code. Cognitive Science, 25, 679-693.

Slowiaczek, L. M. (1990). Effects of lexical stress in auditory word recognition. Language and Speech, 33, 47-68.

Swinney, D. A., Zurif, E., \& Cutler, A. (1980). Effects of sentential stress and word class upon comprehension in Broca's aphasia. Brain and Language, 10, 132-144.

Taft, L. A. (1984). Prosodic constraints and lexical parsing strategies. Doctoral dissertation. University of Massachusetts.

Tyler, L. K., Cobb, H., \& Graham, N. (1992). Spoken language comprehension: An experimental approach to disordered and normal comprehension. Cambridge, 


\section{MA: MIT Press.}

Van Lancker, D. (1980). Cerebral lateralization of pitch cues in the linguistic signal. Papers in Linguistics, 13, 201-277.

Van Lancker, D., \& Sidtis, J. (1992). The identification of affective-prosodic stimuli by left- and right-hemisphere-damaged subjects: All errors are not created equal. Journal of Speech and Hearing Research, 35, 963-970.

Walker, J. P., Fongemie, K., \& Daigle, T. (2001). Prosodic facilitation in the resolution of temporary syntactic ambiguities in subjects with left and right hemisphere damage. Brain and Language, 78, 169-196.

Wayland, S., Wingfield, A., \& Goodglass, H. (1989). Recognition of isolated words: The dynamics of cohort reduction. Applied Psycholinguistics, 10, 475-487.

Weintraub, S., Mesulam, M. M., \& Kramer, L. (1981). Disturbances in prosody: A righthemisphere contribution to language. Archives of Neurology, 38, 742-744.

Wiig, E., \& Secord, W. (1989). Test of language competence-Expanded Edition (TLC-E). San Antonio, Texas: The Psychological Corporation.

Wilson, B., Cockburn, J., Halligan, P. (1987). Behavioural Inattention Test (BIT). UK: Thames Valley Test Company.

Wingfield, A., Goodglass, H., \& Lindfield, K. (1997). Word recognition from acoustic onsets and acoustic offsets: Effects of cohort size and syllabic stress. Applied Psycholinguistics, 18, 85-100.

Wunderlich, A., Ziegler, W., Geigenberger, A. (2003). Implicit processing of prosodic information in patients with left and right hemisphere stroke. Aphasiology, 17 (9), 861-879. 
Table 1

Background Information on Participants

Subject Gender Age (yrs) Education(yrs) MPO* Lesion Site

\begin{tabular}{|c|c|c|c|c|c|}
\hline $\mathrm{NC1}$ & $\mathrm{m}$ & 67 & 11 & & \\
\hline $\mathrm{NC} 2$ & $\mathrm{~m}$ & 73 & 10 & & \\
\hline NC3 & $\mathrm{f}$ & 79 & 18 & & \\
\hline NC4 & $\mathrm{m}$ & 59 & 11 & & \\
\hline NC5 & $\mathrm{f}$ & 69 & 14 & & \\
\hline NC6 & $\mathrm{m}$ & 65 & 19 & & \\
\hline NC7 & $\mathrm{m}$ & 75 & 12 & & \\
\hline NC8 & $\mathrm{f}$ & 64 & 18 & & \\
\hline NC9 & $\mathrm{f}$ & 70 & 12 & & \\
\hline NC10 & $\mathrm{f}$ & 67 & 15 & & \\
\hline NC11 & $\mathrm{f}$ & 79 & 16 & & \\
\hline $\mathrm{NC} 12$ & $\mathrm{~m}$ & 70 & 9 & & \\
\hline NC13 & $\mathrm{f}$ & 77 & 12 & & \\
\hline $\mathrm{NC} 14$ & $\mathrm{~m}$ & 72 & 18 & & \\
\hline Mean & & 70 & 14 & & \\
\hline SD & & 6 & 3 & & \\
\hline LHD1 & $\mathrm{f}$ & 76 & 12 & 114 & L parietal \\
\hline LHD2 & $\mathrm{m}$ & 59 & 10 & 39 & L fronto-temporo-parietal \\
\hline LHD3 & $\mathrm{f}$ & 72 & 9 & 113 & L fronto-temporo-parietal \\
\hline LHD4 & $\mathrm{f}$ & 52 & 14 & 136 & L fronto-parietal with subcortical extensio \\
\hline LHD5 & $\mathrm{f}$ & 71 & 12 & 91 & L fronto-parietal \\
\hline LHD6 & $\mathrm{f}$ & 82 & 16 & 30 & L parietal \\
\hline LHD7 & $\mathrm{m}$ & 84 & 9 & 116 & L frontal \\
\hline LHD8 & $\mathrm{m}$ & 77 & 12 & 145 & L parietal \\
\hline LHD9 & $\mathrm{m}$ & 63 & 20 & 48 & N/A \\
\hline LHD10 & $\mathrm{m}$ & 58 & 16 & 44 & L Perisylvian area \\
\hline Mean & & 69 & 13 & 88 & \\
\hline SD & & 11 & 4 & 43 & \\
\hline RHD1 & $\mathrm{m}$ & 66 & 12 & 30 & $\mathrm{R}$ corona radiata \\
\hline RHD2 & $\mathrm{m}$ & 74 & 14 & 77 & $\mathrm{R}$ thalamus \\
\hline RHD3 & $\mathrm{f}$ & 63 & 13 & 157 & $\mathrm{R}$ posterior communicating artery territor \\
\hline RHD4 & $\mathrm{f}$ & 70 & 13 & 97 & $\mathrm{R}$ basal ganglia \\
\hline RHD5 & $\mathrm{f}$ & 45 & 9 & 77 & R-MCA area \\
\hline RHD6 & $\mathrm{m}$ & 82 & 11 & 70 & $\mathrm{R}$ temporo-parietal \\
\hline RHD7 & $\mathrm{f}$ & 38 & 13 & 94 & R-MCA area \\
\hline RHD8 & $\mathrm{m}$ & 91 & 11 & 76 & N/A \\
\hline RHD9 & $\mathrm{m}$ & 75 & & 22 & N/A \\
\hline Mean & & 67 & 12 & 78 & \\
\hline SD & & 17 & 2 & 39 & \\
\hline
\end{tabular}

*: Months Post Onset, i.e., time since the onset of the neurological lesion 
Table 2

Examples of Stimuli in all Trial Types

\begin{tabular}{lll}
\hline Trial type & Prime & Target \\
\hline CS-R & CANcer & disease \\
CS-UR & PAINter & basis \\
IS-R & feMALE & woman \\
IS-UR & CAffeine & hotel \\
$*$ CS-NW & beLOW & nefius \\
$*$ IS-NW & flyING & zarfer \\
\hline
\end{tabular}

CS/IS=Correct stress or Incorrect Stress Prime

R/UR/NW=Related/ Unrelated or Nonword Target

*=Filler Primes 
Table 3

Individual Subjects' mean RTs for each condition (collapsed across lists)

\begin{tabular}{ccccc}
\hline Subject & CS-R & CS-UR & IS-R & IS-UR \\
\hline NC1 & 888.20 & 894.70 & 869.79 & 910.89 \\
NC2 & 1145.79 & 1213.71 & 1182.53 & 1323.74 \\
NC3 & 1405.47 & 1777.22 & 1423.26 & 1645.47 \\
NC4 & 1263.11 & 1289.33 & 1214.80 & 1268.83 \\
NC5 & 1084.50 & 1126.06 & 1028.45 & 1086.60 \\
NC6 & 865.95 & 988.32 & 846.25 & 977.94 \\
NC7 & 853.47 & 965.11 & 854.60 & 961.95 \\
NC8 & 1102.39 & 1243.84 & 1099.05 & 1186.16 \\
NC9 & 876.84 & 1036.74 & 889.84 & 987.39 \\
NC10 & 744.00 & 932.26 & 762.39 & 993.21 \\
NC11 & 951.26 & 1181.95 & 1047.00 & 1218.63 \\
NC12 & 817.00 & 980.37 & 826.50 & 1004.20 \\
NC13 & 868.16 & 1002.11 & 943.74 & 1087.94 \\
NC14 & 1458.32 & 1575.50 & 1410.32 & 1600.83 \\
\hline Mean & $\mathbf{1 0 7 6 . 1 1}$ & $\mathbf{1 1 8 7 . 2 9}$ & $\mathbf{1 0 6 4 . 8 4}$ & $\mathbf{1 1 7 0 . 2 0}$ \\
S.D & $\mathbf{2 2 5 . 4 8}$ & $\mathbf{2 5 4 . 7 9}$ & $\mathbf{2 1 3 . 4 1}$ & $\mathbf{2 3 1 . 9 9}$ \\
\hline LHD1 & 1045.63 & 1107.61 & 1045.68 & 1068.72 \\
LHD2 & 1036.67 & 1180.39 & 989.15 & 1110.67 \\
LHD3 & 1384.89 & 1523.19 & 1372.68 & 1503.50 \\
LHD4 & 1159.50 & 1229.76 & 1168.00 & 1205.53 \\
LHD5 & 1266.00 & 1307.37 & 1126.61 & 1328.42 \\
LHD6 & 1582.76 & 1695.94 & 1992.58 & 2225.69 \\
LHD7 & 1412.21 & 1345.67 & 1253.94 & 1314.44 \\
LHD8 & 970.00 & 984.89 & 904.95 & 1099.94 \\
LHD9 & 1316.84 & 1361.88 & 1276.32 & 1446.56 \\
LHD10 & 1279.26 & 1521.53 & 1337.89 & 1444.81 \\
\hline Mean & $\mathbf{1 2 4 5 . 3 8}$ & $\mathbf{1 3 2 5 . 8 2}$ & $\mathbf{1 2 4 6 . 7 8}$ & $\mathbf{1 3 7 4 . 8 3}$ \\
S.D & $\mathbf{1 9 2 . 7 8}$ & $\mathbf{2 1 3 . 5 7}$ & $\mathbf{3 0 2 . 8 8}$ & $\mathbf{3 3 7 . 3 2}$ \\
\hline RHD1 & 864.63 & 1050.53 & 898.85 & 971.11 \\
RHD2 & 798.42 & 900.37 & 853.74 & 839.50 \\
RHD3 & 885.28 & 1072.45 & 870.32 & 995.58 \\
RHD4 & 988.67 & 1215.56 & 1037.16 & 1245.72 \\
RHD5 & 972.47 & 1206.61 & 1033.79 & 1004.76 \\
RHD6 & 1286.15 & 1474.40 & 1287.65 & 1326.81 \\
RHD7 & 673.26 & 796.17 & 696.58 & 771.00 \\
RHD8 & 807.59 & 904.29 & 806.00 & 1007.72 \\
RHD9 & 1349.28 & 1371.12 & 1269.68 & 1357.12 \\
\hline Mean & $\mathbf{9 5 8 . 4 2}$ & $\mathbf{1 1 1 0 . 1 7}$ & $\mathbf{9 7 2 . 6 4}$ & $\mathbf{1 0 5 7 . 7 0}$ \\
S.D & $\mathbf{2 2 5 . 0 3}$ & $\mathbf{2 2 6 . 7 0}$ & $\mathbf{2 0 2 . 9 2}$ & $\mathbf{2 0 7 . 3 3}$ \\
\hline & & & &
\end{tabular}




\section{Figure Captions}

Figure 1. Group mean error rates for each condition (collapsed across lists).

Figure 2. Group mean RTs for each condition (collapsed across lists). 


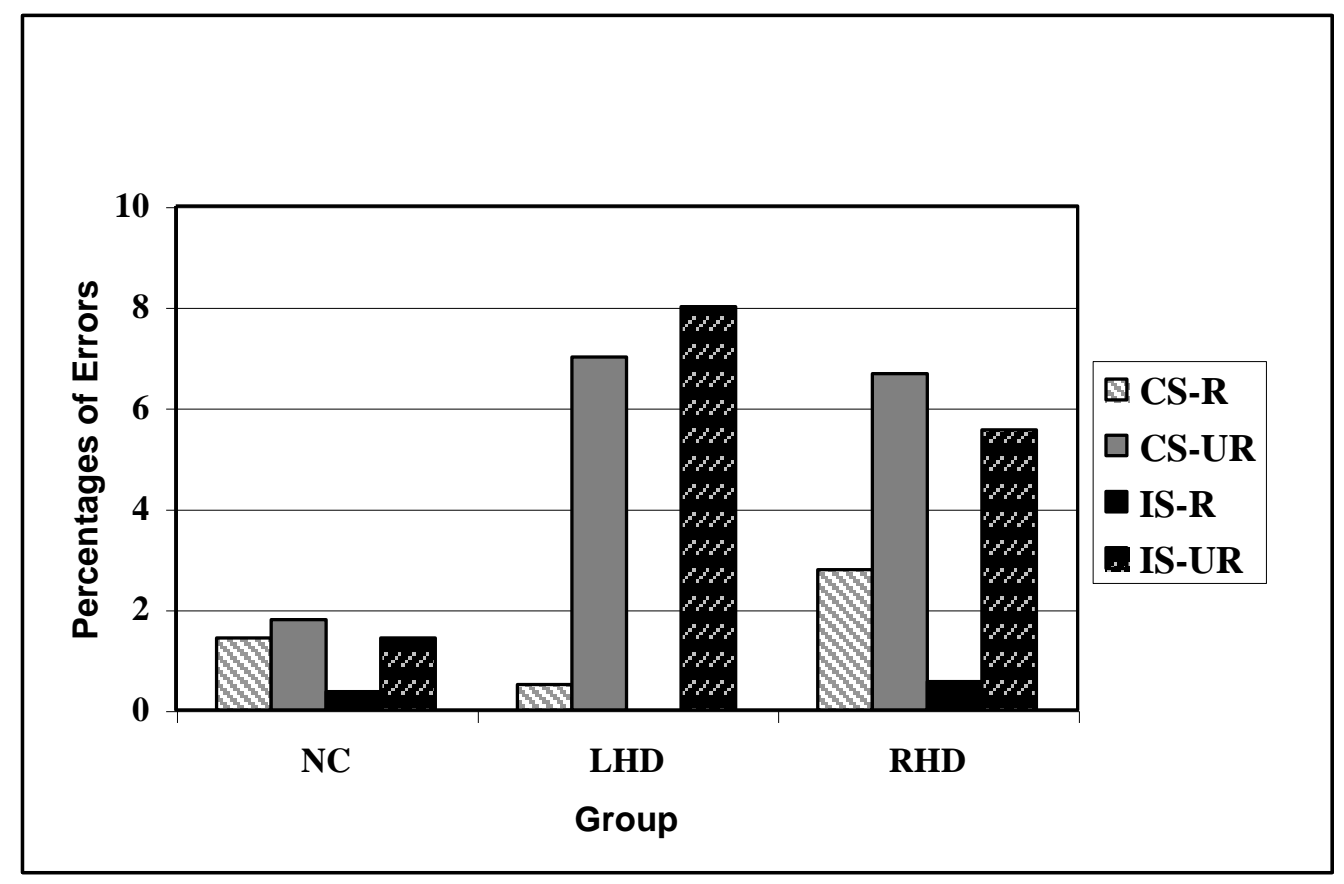




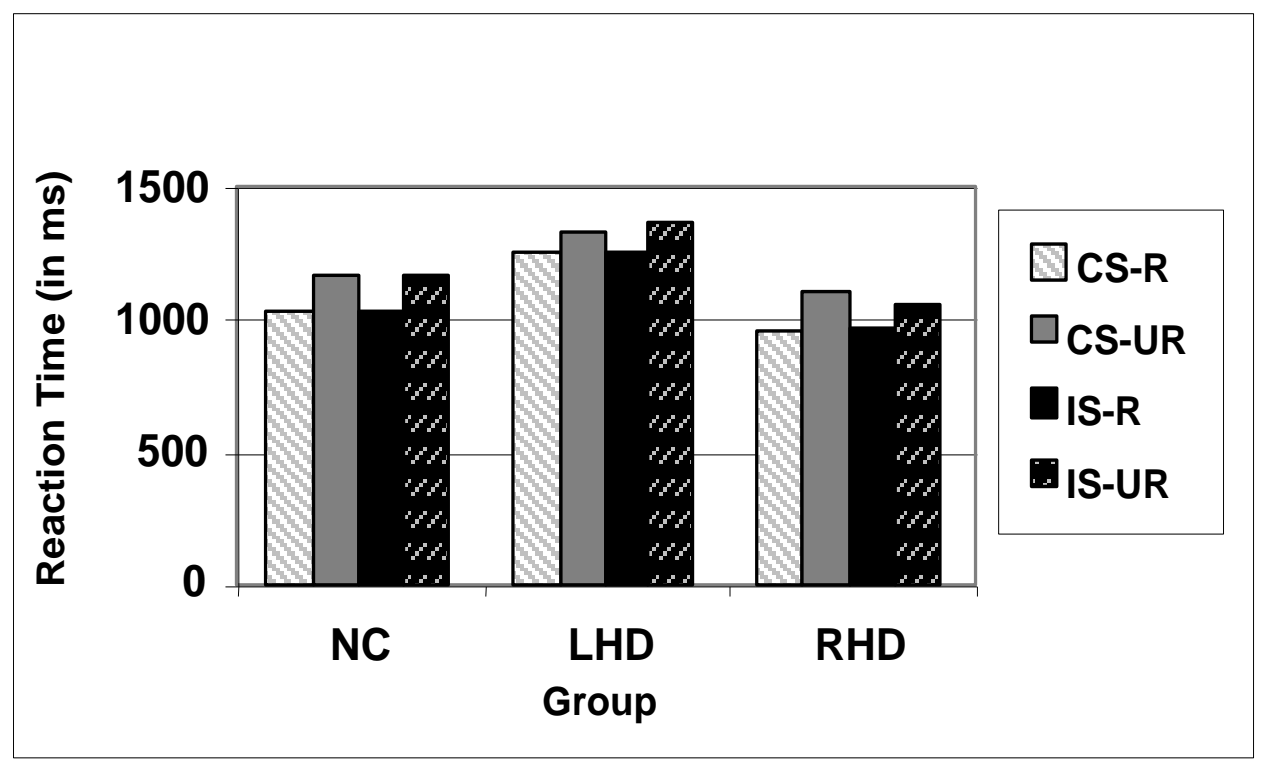


Appendix 1: List of all stimuli

\begin{tabular}{|l|l|l|l|l|l|l|l|}
\hline No. & Prime CS & Prime IS & Target R & Target UR & Filler P CS & Filler P IS & Target NW \\
\hline $\mathbf{1}$ & CANcer & canCER & disease & flower & beLOW & BElow & nefius \\
\hline $\mathbf{2}$ & ACtion & acTION & movement & dinner & FAUcet & fauCET & crolit \\
\hline $\mathbf{3}$ & ALbum & alBUM & record & worker & WInner & wiNNER & pydens \\
\hline $\mathbf{4}$ & aMAZE & Amaze & surprise & amount & USHer & uSHER & liskil \\
\hline $\mathbf{5}$ & ANswer & anSWER & question & effort & CEILing & ceiLING & apstel \\
\hline $\mathbf{6}$ & caFFEINE & CAffeine & coffee & hotel & PHOny & phoNY & blimmen \\
\hline $\mathbf{7}$ & ARmy & arMY & soldier & water & inSANE & INsane & gresar \\
\hline $\mathbf{8}$ & BIRTHday & birthDAY & party & circle & CARpet & carPET & dustag \\
\hline $\mathbf{9}$ & COUNter & counTER & kitchen & body & JOURnal & jourNAL & reptin \\
\hline $\mathbf{1 0}$ & COUNty & counTY & city & table & BOther & boTHER & prepil \\
\hline $\mathbf{1 1}$ & DANcer & danCER & music & building & reJOICE & REjoice & scritty \\
\hline $\mathbf{1 2}$ & FEmale & feMALE & woman & someone & FLYing & flyING & zarfer \\
\hline $\mathbf{1 3}$ & DOllar & doLLAR & money & concept & WASher & waSHER & idarp \\
\hline $\mathbf{1 4}$ & inTENT & INTent & purpose & outside & SYrup & syRUP & filarc \\
\hline $\mathbf{1 5}$ & PAINter & painTER & artist & basis & CHECking & checkING & narny \\
\hline $\mathbf{1 6}$ & FOLder & foIDER & paper & college & TROphy & troPHY & mascin \\
\hline $\mathbf{1 7}$ & PHOto & phoTO & picture & method & diSTRESS & Distress & horlis \\
\hline $\mathbf{1 8}$ & resPONSE & RESponse & answer & father & anNOY & ANNoy & quampted \\
\hline $\mathbf{1 9}$ & STUdent & stuDENT & teacher & window & SEller & seLLER & demphor \\
\hline $\mathbf{2 0}$ & SURgeon & surGEON & doctor & machine & NORmal & norMAL & jegum \\
\hline
\end{tabular}

Legend
CS=Correct Stress Prime
IS=Incorrect Stress Prime
R=Related Target
UR=Unrelated Target
Filler P CS= Filler Correct Stress Prime
Filler I CS=Filler Incorrect Stress Prime
Target NW= Nonword Target

